\title{
REVIEW
}

\section{Copy number variation related disease genes}

\author{
Chaima Aouiche, Xuequn Shang ${ }^{*}$ and Bolin Chen \\ School of Computer Science, Northwestern Polytechnical University, Xi'an 710072, China \\ * Correspondence: shang@nwpu.edu.cn
}

Received September 10, 2017; Revised December 13, 2017; Accepted January 23, 2018

\begin{abstract}
Background: One of the most important and challenging issues in biomedicine and genomics is how to identify disease related genes. Datasets from high-throughput biotechnologies have been widely used to overcome this issue from various perspectives, e.g., epigenomics, genomics, transcriptomics, proteomics, metabolomics. At the genomic level, copy number variations (CNVs) have been recognized as critical genetic variations, which contribute significantly to genomic diversity. They have been associated with both common and complex diseases, and thus have a large influence on a variety of Mendelian and somatic genetic disorders.

Results: In this review, based on a variety of complex diseases, we give an overview about the critical role of using CNVs for identifying disease related genes, and discuss on details the different high-throughput and sequencing methods applied for CNV detection. Some limitations and challenges concerning CNV are also highlighted.

Conclusions: Reliable detection of CNVs will not only allow discriminating driver mutations for various diseases, but also helps to develop personalized medicine when integrating it with other genomic features.
\end{abstract}

Keywords: CNV; disease gene; complex disease; targeted approach; genome-wide approach; whole exome sequencing

\begin{abstract}
Author summary: In this review, we introduce a type of critical genetic variations at the genomic level, copy number variations (CNVs), which contribute significantly to genomic diversity and have proven to be related with a variety of common and rare complex diseases, phenotypes and genetic syndromes as well. Detecting those CNVs plays important roles in these genetic diseases through: (i) identifying disease related genes, their loci and breakpoints, (ii) allowing discrimination of driver mutation for pathogenesis or diagnosis of complex diseases, and (iii) helping to develop personalized medicines. $\mathrm{CNV}$ and its integration with other genomic features will help us understand disease susceptibility and pathogenesis from various perspectives.
\end{abstract}

\section{INTRODUCTION}

Many genetic diseases are not recognized as the result of dysfunction of a single gene [1], but rather related to variations and mutations of multiple genes or their interplays, such as: (i) over- and under-expression of multiple genes [2], (ii) duplicating-/removing of copies of several genes and also (iii) hypo- and hypermethylation of multiple genes. Thus, identification of mutated genes responsible for specific diseases still remains a challenging issue [3]. Reliable detection of these genomic variations and mutated genes is fundamentally important for us to understand the mechanism of many disease or genetic disorder, such as cancers, diabetes, neuropsychiatric disorders [4,5], birth defects, autoimmune disorders, autism and even susceptibility to HIV.

Nowadays, with the development of high-throughput genomic technologies, it has become easy and costeffective to comprehensively characterize various complex diseases by using a wide range of genomic datasets, epigenomic datasets, transcriptomic datasets, proteomic datasets, and metabolomic datasets [6]. Specifically: (i) single-nucleotide polymorphism (SNP), copy number variation $(\mathrm{CNV})$, loss of heterozygosity $(\mathrm{LOH})$, genomic rearrangement are datasets at the genome level; (ii) DNA methylation, histone modification, chromatin accessibility, transcription factor (TF) binding and micro RNA 
(miRNA) are datasets at the epigenome level; (iii) gene expression and alter-native splicing are datasets at the transcriptome level; (iv) protein expression and posttranslational modification are datasets at the proteome level; and (v) metabolite profiling is the dataset at the metabolome level.

Copy number variation (CNV) is one of the most important human genetic variations, which consists of not only sequence variants but also structural variants within populations. Although many genetic variants do not cause overt diseases, they influence disease susceptibility or drug response. Therefore, these CNVs have drawn attention of some scientists and had been recognized as novel genetic variations related to the genomic disease.

The aim of this review is to give insights into the important role of CNVs in the identification of disease related genes. The rest of the paper is organized as follows. In the section of Copy Number Variation Overview, we give a brief overview about the definition of CNVs and their relation with genomic diseases and detection methods. Then, we highlight the most significant disease genes determined using CNV methods. Finally we explain the successful use of this genetic variant in diseases, especially its integration with other genomics data, which will definitely be helpful for identifying new disease genes.

\section{COPY NUMBER VARIATION OVERVIEW}

Along with SNPs (which has been among the most abundant genetic variation in humans), CNVs have attracted many attentions, since they refer to a type of intermediate-scale structural variants (SVs) in the genome. A lot of definitions have been given by many researchers to $\mathrm{CNV}$ as follows:

- CNVs are DNA segments presenting at variable copy numbers and contribute to a substantial proportion of the variation in a genome owing to their large size $[7,8]$.

- CNVs refer to large-scale $(>1 \mathrm{~kb})$ chromosomal copy number changes, e.g., amplifications or deletions compared to a reference genome [9].

- $\mathrm{CNVs}$ are deletions or duplications of size $(>1 \mathrm{~kb})$ genomic area [10].

- CNVs are inherited or de novo structural variations, including all kinds of genomic variations larger than $1 \mathrm{~kb}$, such as insertions, deletions and duplications [11,12].

Briefly, CNVs are defined as either the gain (duplication) or loss (deletion) of a stretch of DNA as compared with a reference genome. They are characterized by the break point loci (starting and ending points), single copy length and number of copies, and they may range in size from a kilobase to several megabase or even an entire chromosome. As depicted in Figure 1.

Additionally, CNVs involve more genomic sequences than SNPs and have potentially greater effects, including alteration of gene dosage, disruption of genes or perturbation of their expression levels. Moreover, CNVs is shown to be enriched in genes also involved in immune responses, cell-cell signaling, and retrovirus- and transposition-related protein coding genes [13]. Thus, based on

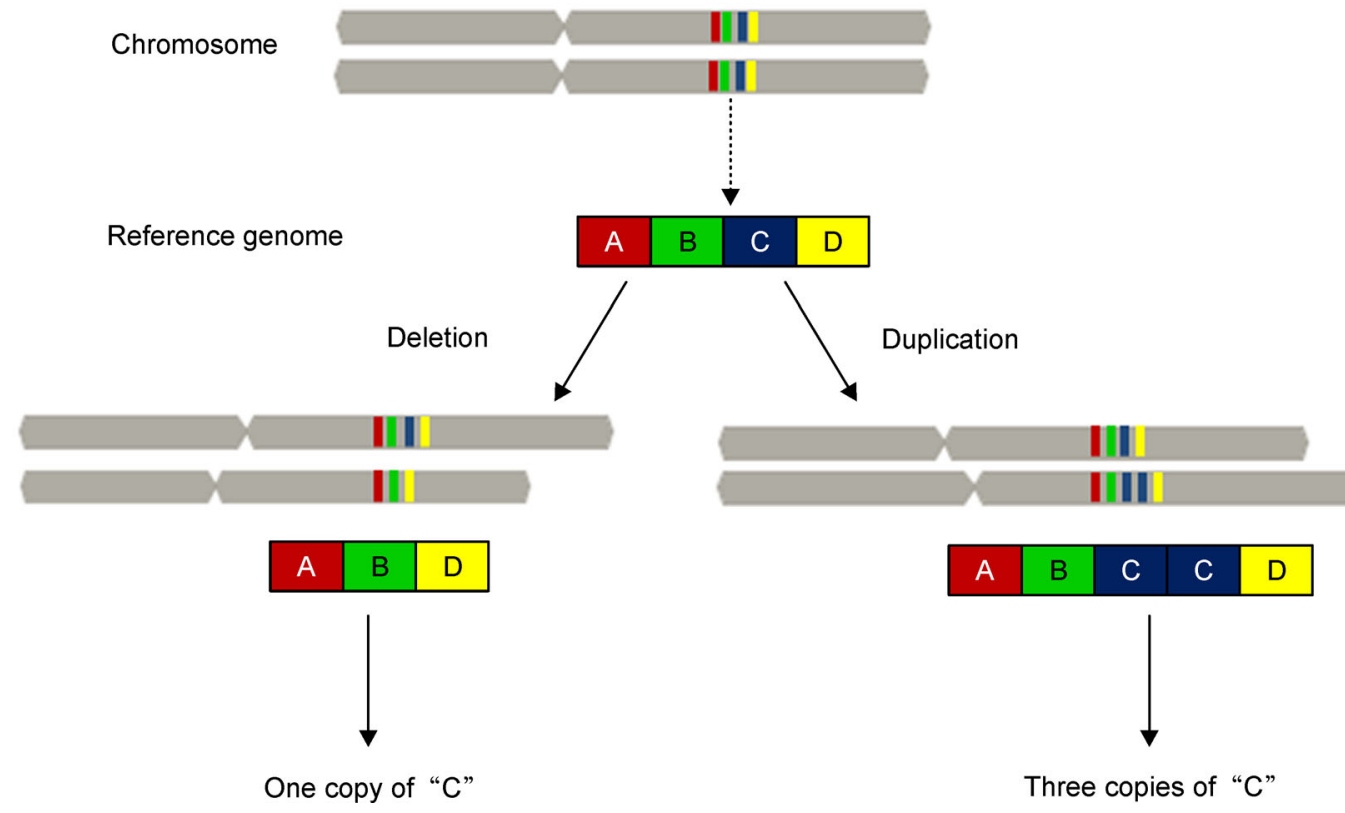

Figure 1. Copy number variations (CNVs). This figure illustrates the typical mechanism of CNV which relatively include duplication and deletion of "C" locus compared to the reference genome (include A, B, C, and D) of the depicted chromosome. 
the large portions of human CNVs that have been reported in the Database of Genomic Variants (DGV) [14-16], and their mild effect on multiple gene functions, many CNVs have been associated with disease susceptibility and severity, while the majority continues to be benign. For example, a duplication within the CCL3L1 (C-C motif chemokine ligand 3 like 1) gene is involved in HIV susceptibility and developing AIDS [17], a deletion within the IRGM (immunity related GTPase M) gene is linked with Crohn's disease [18], a CNV located within the TSPAN8 (tetraspanin 8) gene is associated with type 2 diabetes [19]. Similarly, a lower copy number of $F C G R 3 \mathrm{~B}$ predisposes to immunologically related glomerulonephritis in humans and rats [20] and a higher $E G F R$ copy number is linked to non-small cell lung cancer [21].

$\mathrm{CNV}$ is also associated with a range of neurodevelopmental disorders [22], including autism [23], schizophrenia [24], and depression [25]. Besides neuropsychiatric diseases, CNV have found to be linked with other disease types, including heart disease [26], obesity [27], cancer [28] and it has also been implicated in altered lifespan [29]. Furthermore, CNVs are also linked with extensive phenotypic traits in domestic animals including pigs [30], sheep [31], chicken [32,33], dogs [34], and cattle [35,36] amongst others.

\section{CNV DETECTION METHODS}

Although, CNV studies have developed considerably over time, little is known about how CNVs influence the phenotype of many rare and common complex diseases. To investigate this issue, various CNV detection methods have been developed. These methods can be categorized into two groups [37] (see Table 1 for details):

1. Genome-wide approaches, in which the entire genome is scanned for detecting CNVs. (a) Microarray-based methods [38] such as array comparative genomic hybridization (aCGH) (Figure 2) and single nucleotide polymorphism (SNP) arrays [39].

(b) Karyotyping and fluorescence in situ hybridization (FISH) [40].

(c) Synthetic high-density oligonucleotide arrays [41].

(d) Deep sequencing platforms [42].

(e) NanoString's digital detection technology [43].

(f) Next-generation sequencing (NGS) [44] such as whole genome sequencing (WGS) and whole exome sequencing (WES).

However, genome-wide approach $\mathrm{CNV}$ analyses are not efficient for the validations of a small set of known CNVs. Targeted approaches are more efficient for that purpose.

2. Targeted approaches CNVs include:

(a) Quantitative polymerase chain reaction (qPCR) or southern hybridization for single target screening [45] (Figure 2).

(b) Multiplex ligation-dependent probe amplification (MLPA) [46]. [47].

(c) Multiplex amplifiable probe hybridization (MAPH)

(d) Multiplex amplicon quantification [48].

In this regard, a more extensive commonly and highthroughput methods have been used, especially in the context of CNV related to human genomes. Starting from targeted CNV screening and validation, various methods have been applied including qPCR, paralogue ratio test (PRT), and molecular copy-number counting (MCC). qPCR compares the threshold cycles of a target versus reference sequence. PRT uses a single pair of primers to exploit sequence similarities between the elements of test and reference locus [49]. While MCC uses PCR to count the number of molecules in DNA aliquots [50]. Additionally, multiplex PCR-based approaches such as MAPH, MLPA, MAQ, quantitative multiplex PCR of

Table 1 Dataset: targeted and genome wide approaches

\begin{tabular}{lll}
\hline Approach & & \multicolumn{2}{c}{ Techniques } & \\
\hline Genome-wide approach & Microarray-based & aCGH \\
& SNP-array & \\
& Karyotyping and fluorescence in situ hybridization (FISH) & \\
& Synthetic high-density oligonucleotide arrays & \\
& Deep sequencing platforms & \\
& NanoString's digital detection technology & \\
& NGS-based analyses & Whole-genome sequencing (WGS) \\
& & Whole-exome sequencing (WES) \\
Targeted approach & Quantitative polymerase chain reaction (qPCR) & \\
& Multiplex ligation-dependent probe amplification (MLPA) & \\
& Multiplex amplifiable probe hybridization (MAPH) & \\
& Multiplex amplicon quantification (MAQ) & \\
& &
\end{tabular}


A

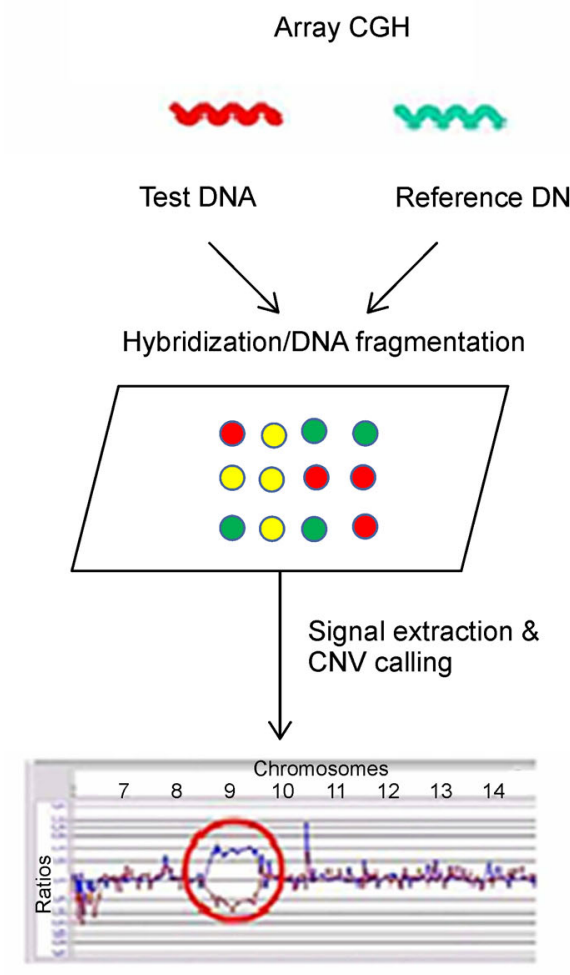

B
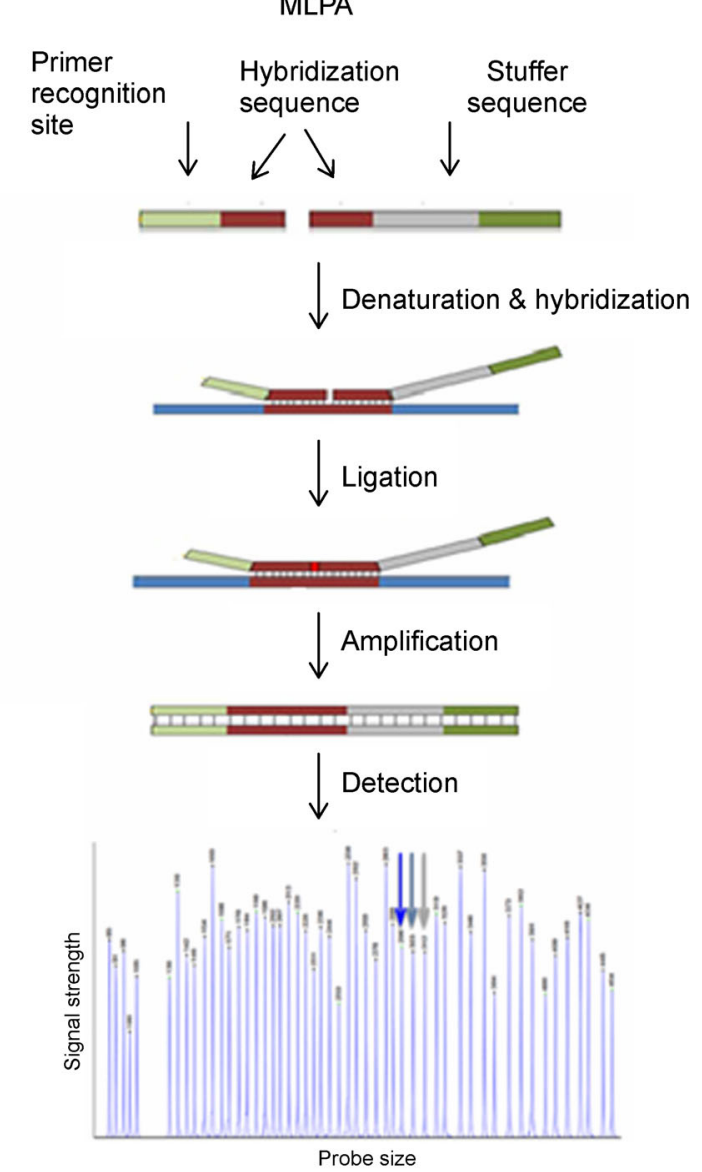

Figure 2. Copy number variation detection methods. (A) Example of genome-wide approach aCGH, test and reference DNA samples are labeled and hybridized onto the whole-genome microarray. Signal intensity ratios are calculated and the copy number differences between the test and reference genome are plotted. (B) Example of targeted approach multiplex ligation-dependent probe amplification (MLPA), each MLPA derived probe oligonucleotide has a different stuffer sequence. The two parts of each probe were hybridized to adjacent target sequences, then ligated and amplified by PCR primer pair. Because of the different lengths of the stuffer sequences, the amplification products of different MLPA probes can be separated, identified, and quantified by capillary electrophoresis.

short fluorescent fragments (QMPSF) and multiplex PCR-based real-time invader assay (mPCR-RETINA), have also been successfully used [51].

On the other hand and from high-throughput perspective, many high-resolution array platforms have been used extensively for $\mathrm{CNV}$ detection, which range from cytogenetic technologies such as karyotyping and fluorescence in situ hybridization (FISH) to more accurate arrays such as CGH and SNP arrays. CGH arrays considered to be a reliable method, since it can measure the fluorescence ratio along the length of each chromosome and identify novel regions of interest in the test sample. This method has the highest sensitivity and specificity [52], but gives relatively low resolution in CNV detection. Similarly, SNP arrays are more commonly used for $\mathrm{CNV}$ analysis, since they provide high resolution of CNVs based on hybridization intensities from custom and non-custom probes and require less sample DNA than CGH [53]. However, the main bias of SNP arrays on CNV detection is the low SNP coverage of the genomic regions.

In the same context of array analysis, a suite of algorithms has been used including but not limited to: CBS [54], GLAD [55], ITALICS [56], CRLMM [57], HMM, PennCNV [58], ParseCNV [59] and R.GADA [60]. Each of these methods has distinctive features and the most of them incorporated $\log \mathrm{R}$ ratio (LRR) and B-allele frequency (BAF) for reliable CNV identification.

To overcome the issues driven by array-based techniques, studies turn to adopt the new approach of NGS, which has rapidly emerged as a viable option to identify CNVs in human diseases. This approach confers a number of critical advantages including higher coverage 
and resolution, more precise detection of breakpoints, and higher capability to identify smaller CNVs [61,62].

In general, three main approaches have been used in NGS technologies: (i) read count, (ii) paired-end and (iii) assembly [63] as shown in Figure 3 plus two additional strategies including split read (SR) and combinatorial of these four methods. In the read depth (RD) approach a sliding window is used to count the number of short reads, and then these read count values are used to identify $\mathrm{CNV}$ regions. RD-based methods can detect the exact number of copy numbers, large insertions, CNVs in complex genomic region classes and can be applied to both WGS and WES data. However, they cannot detect precise breakpoints, inversions and translocations events. Pairedend (PE) approach or paired-end mapping (PEM) identifies genomics aberration based on the distances between a pair of paired-end reads and not single-end reads. Also, PEM is able to identify efficiently inversions and translocations but unable to detect CNVs in low complexity regions. In the assembly (AS) approach overlapping short reads (contigs) are used to assemble the genomics regions, and CNV regions are detected by comparing these assembled contigs to the reference genome. On the other hand, SR methods rely on the only unique mapping information. Since they can only split the incompletely mapped reads of read pairs into multiple fragments, and then the start and end fragments of each split read will be aligned to the reference genome to assign insertion or deletion events. For every approach, a diverse set of popular methods and tools have been developed such as CNV-seq [64], FREEC/ControlFREEC [65], CNVnator [66], SegSeq [67], eventwise testing (EWT) [68], BreakDancer [69], ExomeCNV [70], XHMM [71], ExoCNVTest [72], GPHMM [73], CLImAT [74], Cortex assembler [75] and Magnolya [76]. Although there has been great progress in each category, none of the methods and tools could comprehensively detect all types of CNVs. Thereafter, a combinatorial approach has been used attempting to increase the performance in detecting CNVs more reliably.

Furthermore, several well-established methods have also been used to find recurrent copy number aberration (RCNA) or somatic copy number alteration (SCNA) from a cohort of tumor patients. Among these methods GISTIC (genomic identification of significant targets in cancer) [77], GISTIC 2.0 [78], JIS-TIC [79], NN-SSVD (nonnegative sparse singular value decomposition) [80], DiNAMIC (discovering copy number aberrations manifested in cancer) [81] and PLA (piecewise-constant and low-rank approximation) [82], have extensively applied. All of these methods were focused on the identification of driver aberrations that was proved to be crucial for many diseases progression, unlike passenger events that have no functional effect. GISTIC can identify significant

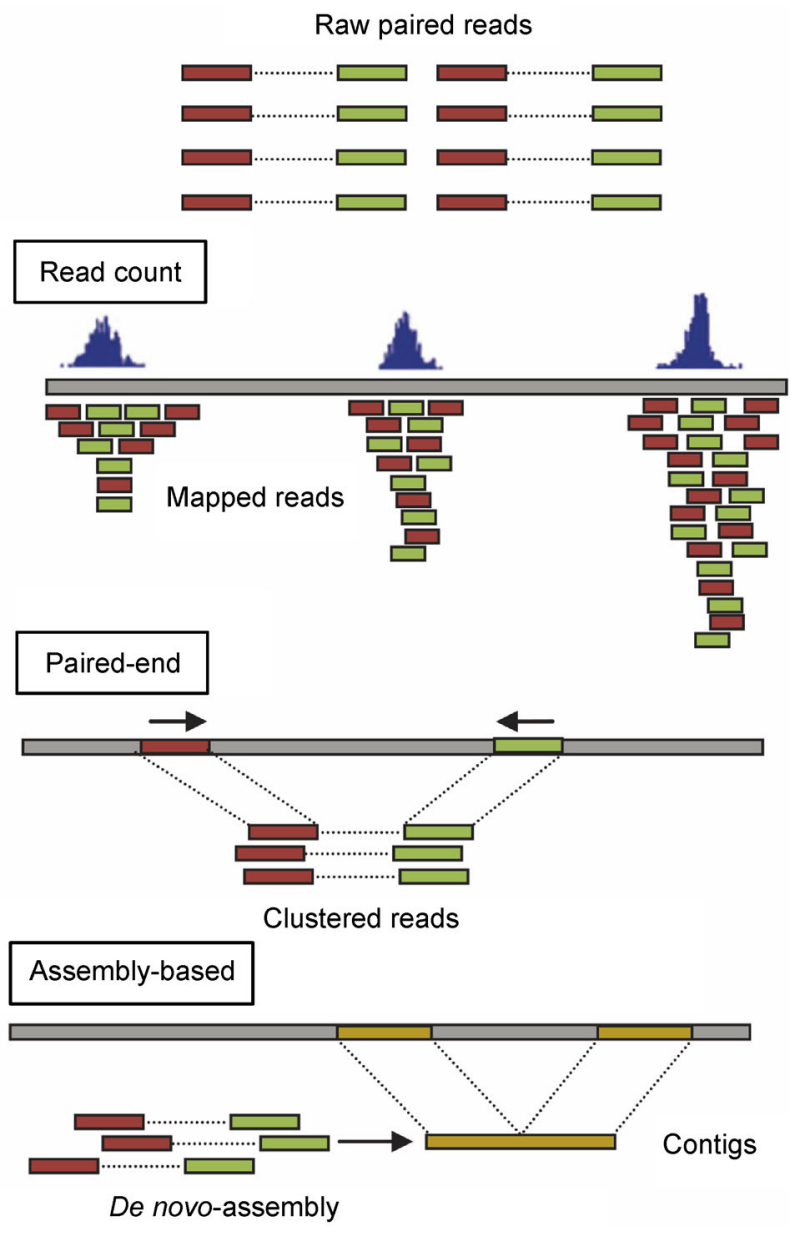

Figure 3. CNV detected approaches from NGS. This figure illustrate the NGS typical methods used to detect CNV.

driver SCNA by evaluating the frequency and amplitude of observed events based on G-score (the product of frequency and average amplitude) and a greedy peelingoff. However, GISTIC 2.0, a revised version of GISTIC discovers recurrent $\mathrm{CNVs}$ based on G-score (the negative logarithm of the likelihood of both frequency and amplitude of each aberration region) and an arbitrated peeling-off. Similarly, JISTIC which is an improved tool of GISTIC algorithm can detect more significant subregions within large aberrant regions. In addition, The RCNA regions of DiNAMIC are detected by using peeling method tailored to the inner cyclic shift procedure from various input-data types (continuous, continuous segmented or discrete segmented). While PLA detects RCNAs by the sample frequency of the low-rank component from multi-sample data, NN-SSVD have the ability to discover RCNAs in complex patterns based on low-rank approximation component of only one layer. 


\section{DISEASES RELATED COPY NUMBER VARIATION}

In this review, we summarize a serious of CNV (common/ rare) related diseases and their associated disease genes. The details of those information are illustrated in the below Tables 2-9 and the following subsections.

\section{Immune response and inflammation}

Various studies have confirmed the significant impact of $\mathrm{CNVs}$ on immune response and inflammation. As initial estimates of the Online Mendelian Inheritance in Man (OMIM) and the Gene Ontology (GO) analysis, large portions of genes and exons as well were linked to CNV and code proteins involved in the immune response and inflammation. For example low copy numbers for the gene $C C L 3 L 1$ were associated with an accelerated rate of HIV progression and developing AIDS (Table 2) [83].

Table 2 Immune response and inflammation

\begin{tabular}{cll}
\hline Disease/phenotype & $\begin{array}{l}\text { Implicated genes } \\
\text { /loci }\end{array}$ & Technique \\
\hline $\begin{array}{c}\text { Immune response } \\
\text { and inflammation }\end{array}$ & $\begin{array}{l}\text { Low copy number } \\
\text { of } C C L 3 L 1\end{array}$ & GO analysis \\
\hline
\end{tabular}

\section{Syndromes, schizophrenia, mental retardation and autism spectrum disorder}

CNVs have been associated with diseases, through (i) dosage of a single gene $[84,85]$, (ii) a contiguous set of genes (e.g., Williams-Beuren syndrome [86,87], DiGeorge syndrome [88], Smith-Magenis syndrome [89], Potocki-Lupski syndrome [90]) or (iii) allele combinations in the case of complex diseases.
Recent studies in (i) syndromes, (ii) schizophrenia [91,92], (iii) mental retardation [93,94] and (iv) autism spectrum disorder [95] not only detected multiple disease related genes but also led to the description of variable phenotypes, novel microdeletion and microduplication syndromes [96-99].

Firstly, in the context of syndromes, various popular classic examples have been identified including (i) the 15q11-q13 deletion associated with Prader-Willi and Angelman syndromes [100], (ii) the $17 \mathrm{p} 11$ deletion associated with Smith-Magenis syndrome [101], (iii) the $7 \mathrm{q} 11$ deletion associated with Williams-Beuren syndrome [102], and (iv) the 22q11 deletions associated with velocardiofacial syndrome (Table 3)[103].

Secondly, alterations in the following three regions were associated with both schizophrenia and mental retardation: (i) $1 \mathrm{q} 21.1$, (ii) $15 \mathrm{q} 11.2$ and (iii) $15 \mathrm{q} 13.3$. While deletions at all three loci were linked to schizophrenia, related psychoses [94,95], as well as 22q11.2 deletion syndrome (22qDS), which is identifiable genetic alteration that has been associated only with schizophrenia [104].

Thirdly, duplication of the entire 15q11-q13.3 and both deletions and duplications of band 1q21.1 were associated with mental retardation.

Finally, duplication of the entire 15q11-q13.3 region was shown to cause autism spectrum disorder (ASD) [95]. Similarly, duplication of band 1q21.1 was also identified in patients with ASD.

These examples suggest that a simple alteration at any given chromosome position in the human genomes can cause some disorders and phenotypes.

\section{Cancers}

It has been specifically reported that an accurate CNVs

Table 3 Syndromes, schizophrenia, mental retardation and autism spectrum disorder

\begin{tabular}{llll}
\hline Disease/phenotype & & Implicated genes/loci & Technique \\
\hline Syndromes & Prader-Willi and Angelman syndromes & Deletion at 15q11-q13 & High-density arrays \\
& Smith-Magenis syndrome & Deletion at $17 \mathrm{p} 11.2$ & High-density arrays \\
& Potocki-Lupski syndrome & Duplication at $17 \mathrm{p} 11.2$ & High-density arrays \\
& Williams-Beuren syndrome & Deletion at $7 \mathrm{q} 11.23$ & High-density arrays \\
& $7 \mathrm{q} 11$ duplication syndrome & $7 \mathrm{q} 11.23$ duplication & High-density arrays \\
& Velocardiofacial syndrome & Deletion at 22q11 & High-density arrays \\
Schizophrenia & Microduplication 22q11.2 & Deletion at 1q21.1, 15q11.2, 15q13.3 & High-density arrays \\
& & $22 \mathrm{q} 11.2$ duplication & High-density arrays \\
Mental retardation & & Duplication at 15q11-q13.3 & High-density arrays \\
& & Duplication and deletion of 1q21.2 & High-density arrays \\
ASD & & Duplication at 15q11-q13.3 & High-density arrays \\
& & Duplication at 1q21.1 & High-density arrays \\
\hline
\end{tabular}


detection is an essential part of cancer genome analysis, which holds great promise to improve cancer prognosis and treatment decision. Therefore, significant effort has found associations between somatic CNVs and cancers, based on their oncogene activation and tumor suppressor gene inactivation caused by copy number amplification and heterozygous/homozygous deletion respectively.

Generally, there are three kinds of CNV variations: (i) Germline CNVs, (ii) somatic CNVs and (iii) inherited $\mathrm{CNV}$. Among these variations, somatic CNVs have been successfully associated with cancer. For example, Walters et al. [105] predicted an amplified copy number of CHD7PVT1 likely to have a relative effect in tumor genesis of small cell lung cancer. Fanciulli et al. have also found associations between somatic CNVs and another kinds of cancers such as prostate and colorectal cancers [83].

In the context of prostate cancer, a landscape of CNVs with the clinical/pathological endpoints of metastasis were observed including that of Barbieri et al. [106] and the Cancer Genome Atlas (TCGA) prostate cancer cohort. The related CNVs include: (i) genomic deletion on chromosomes at $6 \mathrm{p}, 8 \mathrm{p}, 13 \mathrm{q}$ and $16 \mathrm{p}$, (ii) genomic duplication at $7 \mathrm{q}$ and $8 \mathrm{q}$, and (iii) focal alterations spanning PTEN, RB1, and tumor protein p53 (TP53) among others.

Additionally, in the same context of the cancer genome, another disease called oral cavity squamous cell carcinoma (OSCC), including (i) cigarette smoking, (ii) alcohol consumption, and (iii) betel quid chewing, have caused many genomic aberrations and widespread genomic instability, especially in eastern and west countries $[65,107,108]$. Therefore, various studies on OSCC have detected multiple mutations related to genes like: TP53, NOTCH1, CASP8, FAT1, CDKN2A, HRAS, USP9X $[109,110]$ and multiple CNVs events (Table 4) $[109,111,112]$, such as deletions at 3p, 8p, 9p, 18q and duplication at $3 \mathrm{q}, 5 \mathrm{p}, 7 \mathrm{p}, 8 \mathrm{q}, 11 \mathrm{q}$, and $20 \mathrm{q}$.

Furthermore, various methods have also been applied to detect alterations in OSCC heterogeneous patient's samples. Among these methods, an approach called Ultradeep targeted sequencing (UDT-Seq) successfully identified new pathogenic CNVs, like: (i) PIK3CA duplica-tion [113], (ii) FGFR1 duplication [114], and (iii) deletions of PTEN, RB1, SMAD4, and TP53 [114-116].

A suite of studies related to CNVs and their roles in lung cancer have also been discussed. For example, alterations in chromosome regions at 3q26.2-q29, 3p26.3p11.1, 17p13.3-p11.2 and 9p13.3-p13.2 have been deemed as the main predictors for lung cancer. Moreover, an integrative analysis of transcriptional profile and $\mathrm{CNV}$ of lung cancer have captured more significant CNV driven genes.

\section{Cardiovascular disease}

The association of CNVs with cardiovascular diseases has also been early demonstrated. In which, many aberrant

Table 4 Cancers

\begin{tabular}{lll}
\hline Disease/phenotype & Implicated genes/loci & Technique \\
\hline Small cell lung cancer (SCLC) & CHD7-PVT1 & WGS and WES \\
Prostate cancer & Deletion at $6 \mathrm{p}, 8 \mathrm{p}, 13 \mathrm{q}$ and $16 \mathrm{p}$ & WGS and WES \\
& Duplication at 7 and $8 \mathrm{q}$ & WGS and WES \\
& Focal alteration of phosphatase PTEN, RB1, TP53 & WGS and WES \\
OSCC & Deletions at 3p, 8p, 9q, 18q & UDT-Seq \\
& Duplication at 3q, 5p, 7p, 8q, 11q, 20q & UDT-Seq \\
& Duplication of $P I K 3 C A$ & UDT-Seq \\
& Duplication of $F G F R 1$ & UDT-Seq \\
& Deletions of $P T E N, R B 1, S M A D 4$, and $T P 53$ & UDT-Seq \\
Lung cancer ASD & Alteration at 3q26.2-q29.2, 3p26.3-p11.1, 17p13.3-p11.2, 9p13.3-p13.2 & UDT-Seq \\
\hline
\end{tabular}

Table 5 Cardiovascular diseases

\begin{tabular}{lll}
\hline Disease/phenotype & Implicated genes/loci & Technique \\
\hline Ventricular tachycardia & Deletion of Calsequestrin gene at 21p13.2-1p13.1 & aCGH \\
& Duplication of Calsequestrin gene at 21p13.2-1p13.1 & aCGH \\
Hypertrophic cardiomyopathy & Deletion of Myosin, light polypeptide3, alkali at 3p21.31 & aCGH \\
& Deletion of histo-compatibility complex, class2, DR1 at 6p21.32 & aCGH \\
Immune disease and cardiomyopathy & Duplication of histo-compatibility complex, class2, DR1 at 6p21.32 & aCGH \\
\hline
\end{tabular}


CNVs loci and related disease genes have been discovered to strong genetic components often singlegene or "monogenic" disorder (Table 5) [117] such as:

(i) Ventricular tachycardia disease: deletion and duplication of calsequestrin gene at 21p13.2-1p13.1.

(ii) Hypertrophic cardiomyopathy disease: deletion of myosin, light polypeptide 3, alkali at the band 3p21.31.

(iii) Immune disease and cardiomyopathy: deletion and duplication of major histo-compatibility complex, class II, $D R 1$ in $6 \mathrm{p} 21.32$.

\section{Neuropsychiatric disease}

A great number of studies have also demonstrated the role of CNVs in the etiology of several neuropsychiatric disorders [73,117]. Argyrophilic grain disease (AGD) is an example of this genetic disorder. Thus, to identify CNVs related to AGD. They first used aCGH (180k platform) (Table 6) alone and then adopted the same $180 \mathrm{~K}$ aCGH platform with an extra 400 independent samples and revealed no rare CNVs was significant. However, they highlighted a $40 \mathrm{~kb}$ microdeletion at $17 \mathrm{p} 13.2$ that includes the CTNS gene which causes cystinosis disorder, and a $65 \mathrm{~kb}$ deletion that includes the SHPK gene [119].

\section{Autoimmune disorders}

Another genetic disorder called autoimmune disorders have been associated with multiple CNVs rather than single $\mathrm{CNV}$, which is useful for understanding the pathogenesis and discovering new drug targets [120 123]. Several studies have reported this association by discovering several genes such as (Table 7):

(i) Systemic lupus erythematosus (SLE) [122]: Fcy receptors located at $6 \mathrm{p} 21$, complement component $4(\mathrm{C} 4)$ at $1 \mathrm{q} 23$ positions, $R A B G A P 1 L$, and deletion at $10 \mathrm{q} 21.3$ deletion.

(ii) Psoriasis and Crohn's disease (CD): ITP and bdefensin genes.

(iii) Rheumatoid arthritis (RA): VPREB1 at 22q11 region.

(iv) Ankylosing spondylitis (AS) [76]: deletion of HHAT (1q32.2), HLA-DPB1 (6p21.3), PRKRA (2q31.2), EEF1DP3 (13q13.1) and 16p13.3.

\section{Psoriasis}

In contrast to most complex diseases, the role of common $\mathrm{CNV}$ in the pathogenesis of psoriasis has been well addressed across multiple studies [123-126]. Particularly, a promising association between psoriasis and a $32.2 \mathrm{~kb}$ deletion of $L C E 3 B$ and $L C E 3 C$ genes have been identified extensively in (i) in European populations [123], and (ii) subsequently replicated in a Chinese cohort [126], and then confirmed extremely by ExoCNV Test exome sequencing method (Table 8).

\section{Huntington's disease}

While it is known that gene deletion and duplication can affect neurological disease, a new study was also able to investigate an association between $\mathrm{CNV}$ and variable adult age of onset (AAO) of Huntington's disease (HD). As a result, $\mathrm{CNV}$ of $S L C 2 A 3$ has been finally observed between 1 copy (heterozygous deletion) and 3 copies (heterozygous duplication) in HD [127], whereas many genes and loci were related extensively to neurodegenerative disorders such as the triplication of alphasynuclein or large deletions of the parkin gene causing Parkinson's disease [128].

Table 6 Neuropsychiatric disease

\begin{tabular}{lll}
\hline Disease/phenotype & Implicated genes/loci & Technique \\
\hline AGD & Microdeletion of CTNS at 17p13 & aCGH \\
Cystinosis & Deletion of SHPK & aCGH \\
\hline
\end{tabular}

Table 7 Autoimmune disorders

\begin{tabular}{lll}
\hline Disease/phenotype & Implicated genes/loci & Technique \\
\hline Systemic lupus erythematosus (SLE) & FCy receptor at 6p21, & GWA \\
& C4 at 1q23, RABGAP1L, GWA \\
Psoriasis and Crohns disease (CD) & Deletion at 10q21 & GWA \\
Rheumatoid arthritis (RA) & ITP, b-defensin & GWA \\
Ankylosing spondylitis (AS) & VPREB1 at 22q.11 & GWA \\
& Deletion of HHAT (1q32.2), & GWA \\
& HLA-DPB1 (6p21.3), PRKRA (2q31.2), & GWA \\
\hline
\end{tabular}


Table 8 Psoriasis

\begin{tabular}{lll}
\hline Disease/phenotype & Implicated genes/loci & Technique \\
\hline Psoriasis & $32.2 \mathrm{~kb}$ deletion of $L C E 3 B-L C E 3 C$ & WES, ExoCNV \\
\hline
\end{tabular}

Table 9 Huntington's disease (HD)

\begin{tabular}{ll}
\hline Disease/phenotype & Implicated genes/loci \\
\hline Huntington's disease (HD) & SLC2A3 \\
\hline
\end{tabular}

\section{CONCLUSIONS}

Nowadays, with advances in high-throughput genomic technologies, various genomic datasets have been significantly reported from various biological levels. In this review, we have focused on CNVs which belong to the genomic level. An overview of the definition of CNVs, CNVs related diseases/phenotypes and detections methods has been firstly introduced. Then, based on a number of complex diseases, the critical role of CNVs (whether rare or common CNVs) have been summarized for the identification of disease related genes.

To date, a large number of genetic diseases and phenotypes have been associated with CNVs. CNVs play important roles in these genetic diseases through: (i) identifying multiple genes whether existed genes or newly discovered ones, (ii) allowing discrimination of driver mutation for pathogenesis or diagnosis of complex diseases and (iii) helping to develop personalized medicines.

Various methods have been discovered to validate and detect the reliability and the accuracy of CNVs. These methods are: (i) cytogenetics and karyotyping methods, (ii) microarrays based methods, (iii) next generation sequencing methods and (iv) third generation approaches as well. Each of these approaches has advantages and disadvantages, which are: coverage biases, batch effects, poor sensitivity and precision as well as higher effective resolution and less complex data analysis. However, accurate detection of small CNVs specifically and their precise boundaries from massively amount of data using these methods is still a challenge, which largely due to the complexities of tumor samples. Thus, the validity and reliability detection of CNVs will improve quickly as genotyping technologies advance, which will support the required replication.

In addition, the role of CNVs in genetic syndromes has long been recognized, with recurrent microdeletion/ microduplications detected in syndromes, such as Prader-Willi, Smith-Magenis and Williams-Beuren. However, with the increased clinical use of array-based CNV analysis, the list of CNVs associated with disease phenotypes has continued to grow. This has led to the discovery of many new microdeletion and microduplica- tion syndromes. These novel syndromes and the everexpanding of CNVs associated with disease phenotypes, highlight the significant involvement of CNVs in genetic diseases.

An important issue that has also to be reported in the context of CNVs was called missing heritability [129]. This issue has been studied in order to estimate the heritability of common diseases. Missing heritability in genome wide association studies, which was identified as the failure to account for a considerable fraction of heritability by the variants detected is also still a challenging issue in human genetics. For solving this puzzle, a number of $\mathrm{CNV}$ based methods have been proposed. However, none of them have accurately accounted for missing heritability due to the conflict raised from rare and common genetic variants.

In conclusion, $\mathrm{CNV}$ alone will not meet a great advancement enough and will not be a worthy endeavor enough without its integration with other genomic datasets. Multiple data integrations have proved to be successful, which include those datasets such as gene expression, DNA methylation, protein-protein interaction (PPI), metabolism pathways and Gene Ontology. These integrations will help us understand disease susceptibility and pathogenesis from various perspectives.

\section{AUTHOR'S CONTRIBUTIONS}

Bolin Chen initiated this review work; Chaima Aouiche and Bolin Chen discussed the whole outline and designed the review topics; Chaima Aouiche wrote the paper; Chaima Aouiche, Xuequn Shang and Bolin Chen revised the manuscript for many times throughly. All authors have read and approved the final manuscript.

\section{ACKNOWLEDGEMENTS}

This work was supported by the National Natural Science Foundation of China (Nos. 61602386 and 61332014), the Natural Science Foundation of Shaanxi Province (No. 2017JQ6008), and the top university visiting foundation for excellent youth scholars of Northwestern Polytechnical University.

\section{COMPLIANCE WITH ETHICS GUIDELINES}

The authors Chaima Aouiche, Xuequn Shang and Bolin Chen declare that they have no conflict of interests. 
This article is a review article does not contain any studies with human or animal subjects performed by any of the authors.

\section{REFERENCES}

1. Schadt, E. E. (2009) Molecular networks as sensors and drivers of common human diseases. Nature, 461, 218-223

2. Goh, K. I., Cusick, M. E., Valle, D., Childs, B., Vidal, M. and Barabási, A. L. (2007) The human disease network. Proc. Natl. Acad. Sci. USA, 104, 8685-8690

3. Davies, R. J., Miller, R. and Coleman, N. (2005) Colorectal cancer screening: prospects for molecular stool analysis. Nat. Rev. Cancer, 5, 199-209

4. Beckmann, J. S., Estivill, X. and Antonarakis, S. E. (2007) Copy number variants and genetic traits: closer to the resolution of phenotypic to genotypic variability. Nat. Rev. Genet., 8, 639-646

5. Beroukhim, R., Mermel, C. H., Porter, D., Wei, G., Raychaudhuri, S., Donovan, J., Barretina, J., Boehm, J. S., Dobson, J., Urashima, M., et al. (2010) The landscape of somatic copynumber alteration across human cancers. Nature, 463, 899-905

6. Ritchie, M. D., Holzinger, E. R., Li, R., Pendergrass, S. A. and Kim, D. (2015) Methods of integrating data to uncover genotypephenotype interactions. Nat. Rev. Genet., 16, 85-97

7. Ionita-Laza, I., Rogers, A. J., Lange, C., Raby, B. A. and Lee, C. (2009) Genetic association analysis of copy-number variation $(\mathrm{CNV})$ in human disease pathogenesis. Genomics, 93, 22-26

8. Redon, R., Ishikawa, S., Fitch, K. R., Feuk, L., Perry, G. H., Andrews, T. D., Fiegler, H., Shapero, M. H., Carson, A. R., Chen, W., et al. (2006) Global variation in copy number in the human genome. Nature, 444, 444-454

9. Freeman, J. L., Perry, G. H., Feuk, L., Redon, R., McCarroll, S. A., Altshuler, D. M., Aburatani, H., Jones, K. W., Tyler-Smith, C., Hurles, M. E., et al. (2006) Copy number variation: new insights in genome diversity. Genome Res., 16, 949-961

10. Stankiewicz, P. and Lupski, J. R. (2010) Structural variation in the human genome and its role in disease. Annu. Rev. Med., 61, 437455

11. Feuk, L., Carson, A. R. and Scherer, S. W. (2006) Structural variation in the human genome. Nat. Rev. Genet., 7, 85-97

12. Eichler, E. E., Nickerson, D. A., Altshuler, D., Bowcock, A. M., Brooks, L. D., Carter, N. P., Church, D. M., Felsenfeld, A., Guyer, M., Lee, C., et al. (2007) Completing the map of human genetic variation. Nature, 447, 161-165

13. Li, W. and Olivier, M. (2013) Current analysis platforms and methods for detecting copy number variation. Physiol. Genomics, $45,1-16$

14. Iafrate, A. J., Feuk, L., Rivera, M. N., Listewnik, M. L., Donahoe, P. K., Qi, Y., Scherer, S. W. and Lee, C. (2004) Detection of largescale variation in the human genome. Nat. Genet., 36, 949-951

15. Sebat, J., Lakshmi, B., Troge, J., Alexander, J., Young, J., Lundin, P., Månér, S., Massa, H., Walker, M., Chi, M., et al. (2004) Largescale copy number polymorphism in the human genome. Science, $305,525-528$

16. Zhang, J., Feuk, L., Duggan, G. E., Khaja, R. and Scherer, S. W. (2006) Development of bioinformatics resources for display and analysis of copy number and other structural variants in the human genome. Cytogenet. Genome Res., 115, 205-214

17. Gonzalez, E., Kulkarni, H., Bolivar, H., Mangano, A., Sanchez, R., Catano, G., Nibbs, R., Freedman, B., Marlon P. , Quinones, M., Bamshad, M., et al. (2005) The influence of CCL3L1 genecontaining segmental duplications on HIV-1/AIDS susceptibility. Science, 307, 1434-1440

18. McCarroll, S. A., Huett, A., Kuballa, P., Chilewski, S. D., Landry, A., Goyette, P., Zody, M. C., Hall, J. L., Brant, S. R., Cho, J. H., et al. (2008) Deletion polymorphism upstream of IRGM associated with altered IRGM expression and Crohn's disease. Nat. Genet., 40, 1107-1112

19. Craddock, N., Hurles, M. E., Cardin, N., Pearson, R. D., Plagnol, V., Robson, S., Vukcevic, D., Barnes, C., Conrad, D. F., Giannoulatou, E., et al. (2010) Genome-wide association study of CNVs in 16,000 cases of eight common diseases and 3,000 shared controls. Nature, 464, 713-720

20. Aitman, T. J., Dong, R., Vyse, T. J., Norsworthy, P. J., Johnson, M. D., Smith, J., Mangion, J., Roberton-Lowe, C., Marshall, A. J., Petretto, E., et al. (2006) Copy number polymorphism in Fcgr3 predisposes to glomerulonephritis in rats and humans. Nature, 439, 851-855

21. Cappuzzo, F., Hirsch, F. R., Rossi, E., Bartolini, S., Ceresoli, G. L., Bemis, L., Haney, J., Witta, S., Danenberg, K., Domenichini, I., et al. (2005) Epidermal growth factor receptor gene and protein and gefitinib sensitivity in non-small-cell lung cancer. J. Natl. Cancer Inst., 97, 643-655

22. Glessner, J. T., Connolly, J. J. and Hakonarson, H. (2012) Rare genomic deletions and duplications and their role in neurodevelopmental disorders. Curr. Top. Behav. Neurosci., 12, 345-360

23. Glessner, J. T., Wang, K., Cai, G., Korvatska, O., Kim, C. E., Wood, S., Zhang, H., Estes, A., Brune, C. W., Bradfield, J. P., et al. (2009) Autism genome-wide copy number variation reveals ubiquitin and neuronal genes. Nature, 459, 569-573

24. Glessner, J. T., Reilly, M. P., Kim, C. E., Takahashi, N., Albano, A., Hou, C., Bradfield, J. P., Zhang, H., Sleiman, P. M., Flory, J. H., et al. (2010) Strong synaptic transmission impact by copy number variations in schizophrenia. Proc. Natl. Acad. Sci. USA, 107, 10584-10589

25. Glessner, J. T., Wang, K., Sleiman, P. M., Zhang, H., Kim, C. E., Flory, J. H., Bradfield, J. P., Imielinski, M., Frackelton, E. C., Qiu, H., et al. (2010) Duplication of the SLIT3 locus on 5q35.1 predisposes to major depressive disorder. PLoS One, 5, e15463

26. Goldmuntz, E., Paluru, P., Glessner, J., Hakonarson, H., Biegel, J. A., White, P. S., Gai, X. and Shaikh, T. H. (2011) Microdeletions and microduplications in patients with congenital heart disease and multiple congenital anomalies. Congenit. Heart Dis., 6, 592 602

27. Glessner, J. T., Bradfield, J. P., Wang, K., Takahashi, N., Zhang, H., Sleiman, P. M., Mentch, F. D., Kim, C. E., Hou, C., Thomas, K. A., et al. (2010) A genome-wide study reveals copy number variants exclusive to childhood obesity cases. Am. J. Hum. Genet., 87, 661-666

28. Kuusisto, K. M., Akinrinade, O., Vihinen, M., Kankuri- 
Tammilehto, M., Laasanen, S. L. and Schleutker, J. (2013) copy number variation analysis in familial $B R C A 1 / 2$-negative Finnish breast and ovarian cancer PLoS One, 8, e71802

29. Glessner, J. T., Smith, A. V., Panossian, S., Kim, C. E., Takahashi, N., Thomas, K. A., Wang, F., Seidler, K., Harris, T. B., Launer, L. J., et al. (2013) Copy number variations in alternative splicing gene networks impact lifespan. PLoS One, 8, e53846

30. Johansson Moller, M., Chaudhary, R., Hellmén, E., Höyheim, B., Chowdhary, B. and Andersson, L. (1996) Pigs with the dominant white coat color phenotype carry a duplication of the KIT gene encoding the mast/stem cell growth factor receptor. Mamm. Genome, 7, 822-830

31. Norris, B. J. and Whan, V. A. (2008) A gene duplication affecting expression of the ovine ASIP gene is responsible for white and black sheep. Genome Res., 18, 1282-1293

32. Wright, D., Boije, H., Meadows, J. R. S., Bed'hom, B., Gourichon, D., Vieaud, A., Tixier-Boichard, M., Rubin, C. J., Imsland, F., Hallböök, F., et al. (2009) Copy number variation in intron 1 of SOX5 causes the Pea-comb phenotype in chickens. PLoS Genet., 5, e1000512

33. Dorshorst, B., Harun-Or-Rashid, M., Bagherpoor, A. J., Rubin, C. J., Ashwell, C., Gourichon, D., Tixier-Boichard, M., Hallböök, F. and Andersson, L. (2015) A genomic duplication is associated with ectopic eomesodermin expression in the embryonic chicken comb and two duplex-comb phenotypes. PLoS Genet., 11, e1004947

34. Salmon Hillbertz, N. H. C., Isaksson, M., Karlsson, E. K., Hellmén, E., Pielberg, G. R., Savolainen, P., Wade, C. M., von Euler, H., Gustafson, U., Hedhammar, A., et al. (2007) Duplication of FGF3, FGF4, FGF19 and ORAOV1 causes hair ridge and predisposition to dermoid sinus in Ridgeback dogs. Nat. Genet., 39, 1318-1320

35. Drögemüller, C., Distl, O. and Leeb, T. (2001) Partial deletion of the bovine $E D 1$ gene causes anhidrotic ectodermal dysplasia in cattle. Genome Res., 11, 1699-1705

36. Capitan, A., Allais-Bonnet, A., Pinton, A., Marquant-Le Guienne, B., Le Bourhis, D., Grohs, C., Bouet, S., Clément, L., Salas-Cortes, L., Venot, E., et al. (2012) A 3.7 Mb deletion encompassing ZEB2 causes a novel polled and multisystemic syndrome in the progeny of a somatic mosaic bull. PLoS One, 7 , e49084

37. Aten, E., White, S. J., Kalf, M. E., Vossen, R. H., Thygesen, H. H., Ruivenkamp, C. A., Kriek, M., Breuning, M. H. and den Dunnen, J. T. (2008) Methods to detect CNVs in the human genome. Cytogenet. Genome Res., 123, 313-321

38. Kim, T. M., Yim, S. H. and Chung, Y. J. (2008) Copy number variations in the human genome: potential source for individual diversity and disease association studies. Genomics Inform., 6, 17

39. Carter, N. P. (2007) Methods and strategies for analyzing copy number variation using DNA microarrays. Nat. Genet., 39, S16S21

40. Buysse, K., Delle Chiaie, B., Van Coster, R., Loeys, B., De Paepe, A., Mortier, G., Speleman, F., Menten, B. (2009) Challenges for
CNV interpretation in clinical molecular karyotyping: lessons learned from a 1,001 sample experience. Eur. J. Med. Gene., 52, 398-403

41. Lucito, R., Healy, J., Alexander, J., Reiner, A., Esposito, D., Chi, M., Rodgers, L., Brady, A., Sebat, J., Troge, J., et al. (2003) Representational oligonucleotide microarray analysis: a highresolution method to detect genome copy number variation. Genome Res., 13, 2291-2305

42. Chiang, D. Y., Getz, G., Jaffe, D. B., O'Kelly, M. J., Zhao, X., Carter, S. L., Russ, C., Nusbaum, C., Meyerson, M. and Lander, E. S. (2009) High-resolution mapping of copy-number alterations with massively parallel sequencing. Nat. Methods, 6, 99-103

43. Geiss, G. K., Bumgarner, R. E., Birditt, B., Dahl, T., Dowidar, N., Dunaway, D. L., Fell, H. P., Ferree, S., George, R. D., Grogan, T., et al. (2008) Direct multiplexed measurement of gene expression with color-coded probe pairs. Nat. Biotechnol., 26, 317-325

44. Abel, H. J. and Duncavage, E. J. (2013) Detection of structural DNA variation from next generation sequencing data: a review of informatic approaches. Cancer Genet., 206, 432-440

45. Weksberg, R., Hughes, S., Moldovan, L., Bassett, A. S., Chow, E. W. and Squire, J. A. (2005) A method for accurate detection of genomic microdeletions using real-time quantitative PCR. BMC Genomics, 6, 180

46. Schouten, J. P., McElgunn, C. J., Waaijer, R., Zwijnenburg, D., Diepvens, F. and Pals, G. (2002) Relative quantification of 40 nucleic acid sequences by multiplex ligation-dependent probe amplification. Nucleic Acids Res., 30, e57

47. Armour, J. A., Sismani, C., Patsalis, P. C. and Cross, G. (2000) Measurement of locus copy number by hybridisation with amplifiable probes. Nucleic Acids Res., 28, 605-609

48. Kumps, C., Van Roy, N., Heyrman, L., Goossens, D., Del-Favero, J., Noguera, R., Vandesompele, J., Speleman, F. and De Preter, K. (2010) Multiplex amplicon quantification (MAQ), a fast and efficient method for the simultaneous detection of copy number alterations in neuroblastoma. BMC Genomics, 11, 298

49. Fernandez-Jimenez, N., Castellanos-Rubio, A., Plaza-Izurieta, L., Gutierrez, G., Irastorza, I., Castaño, L., Vitoria, J. C. and Bilbao, J. R. (2011) Accuracy in copy number calling by qPCR and PRT: a matter of DNA. PLoS One, 6, e28910

50. Daser, A., Thangavelu, M., Pannell, R., Forster, A., Sparrow, L., Chung, G., Dear, P. H. and Rabbitts, T. H. (2006) Interrogation of genomes by molecular copy-number counting (MCC). Nat. Methods, 3, 447-453

51. Ceulemans, S., van der Ven, K. and Del-Favero, J. (2012) Targeted screening and validation of copy number variations. Methods Mol. Biol., 838, 311-328

52. Haraksingh, R. R., Abyzov, A., Gerstein, M., Urban, A. E. and Snyder, M. (2011) Genome-wide mapping of copy number variation in humans: comparative analysis of high resolution array platforms. PLoS One, 6, e27859

53. Oldridge, D. A., Banerjee, S., Setlur, S. R., Sboner, A. and Demichelis, F. (2010) Optimizing copy number variation analysis using genome-wide short sequence oligonucleotide arrays. Nucleic Acids Res., 38, 3275-3286 
54. Olshen, A. B., Venkatraman, E. S., Lucito, R. and Wigler, M. (2004) Circular binary segmentation for the analysis of arraybased DNA copy number data. Biostatistics, 5, 557-572

55. Hupé, P., Stransky, N., Thiery, J. P., Radvanyi, F. and Barillot, E. (2004) Analysis of array CGH data: from signal ratio to gain and loss of DNA regions. Bioinformatics, 20, 3413-3422

56. Rigaill, G., Hupé, P., Almeida, A., La Rosa, P., Meyniel, J. P., Decraene, C. and Barillot, E. (2008) ITALICS: an algorithm for normalization and DNA copy number calling for Affymetrix SNP arrays. Bioinformatics, 24, 768-774

57. Scharpf, R. B., Ruczinski, I., Carvalho, B., Doan, B., Chakravarti, A. and Irizarry, R. A. (2011) A multilevel model to address batch effects in copy number estimation using SNP arrays. Biostatistics, $12,33-50$

58. Wang, K., Li, M., Hadley, D., Liu, R., Glessner, J., Grant, S. F., Hakonarson, H. and Bucan, M. (2007) PennCNV: an integrated hidden Markov model designed for high-resolution copy number variation detection in whole-genome SNP genotyping data. Genome Res., 17, 1665-1674

59. Glessner, J. T., Li, J. and Hakonarson, H. (2013) ParseCNV integrative copy number variation association software with quality tracking. Nucleic Acids Res., 41, e64

60. Pique-Regi, R., Cáceres, A. and González, J. R. (2010) R-Gada: a fast and flexible pipeline for copy number analysis in association studies. BMC Bioinformatics, 11, 380

61. Alkan, C., Coe, B. P. and Eichler, E. E. (2011) Genome structural variation discovery and genotyping. Nat. Rev. Genet., 12, 363376

62. Meyerson, M., Gabriel, S. and Getz, G. (2010) Advances in understanding cancer genomes through second-generation sequencing. Nat. Rev. Genet., 11, 685-696

63. Zhao, M., Wang, Q., Wang, Q., Jia, P. and Zhao, Z. (2013) Computational tools for copy number variation (CNV) detection using next-generation sequencing data: fea-tures and perspectives. BMC Bioinformatics, 14 (Suppl 11), S1

64. Xie, C. and Tammi, M. T. (2009) CNV-seq, a new method to detect copy number variation using high-throughput sequencing. BMC Bioinformatics, 10, 80

65. Boeva, V., Zinovyev, A., Bleakley, K., Vert, J. P., JanoueixLerosey, I., Delattre, O. and Barillot, E. (2011) Control-free calling of copy number alterations in deep-sequencing data using GC-content normalization. Bioinformatics, 27, 268-269

66. Abyzov, A., Urban, A. E., Snyder, M. and Gerstein, M. (2011) CNVnator: an approach to discover, genotype, and characterize typical and atypical CNVs from family and population genome sequencing. Genome Res., 21, 974-984

67. Chiang, D. Y., Getz, G., Jaffe, D. B., O’Kelly, M. J. T., Zhao, X., Carter, S. L., Russ, C., Nusbaum, C., Meyerson, M. and Lander, E. S. (2009) High-resolution mapping of copy-number alterations with massively parallel sequencing. Nat. Methods, 6, 99-103

68. Yoon, S., Xuan, Z., Makarov, V., Ye, K. and Sebat, J. (2009) Sensitive and accurate detection of copy number variants using read depth of coverage. Genome Res., 19, 1586-1592

69. Chen, K., Wallis, J. W., McLellan, M. D., Larson, D. E., Kalicki,
J. M., Pohl, C. S., McGrath, S. D., Wendl, M. C., Zhang, Q., Locke, D. P., et al. (2009) BreakDancer: an algorithm for highresolution mapping of genomic structural variation. Nat. Methods, 6, 677-681

70. Sathirapongsasuti, J. F., Lee, H., Horst, B. A., Brunner, G., Cochran, A. J., Binder, S., Quackenbush, J. and Nelson, S. F. (2011) Exome sequencing-based copy-number variation and loss of heterozygosity detection: ExomeCNV. Bioinformatics, 27, 2648-2654

71. Fromer, M., Moran, J. L., Chambert, K., Banks, E., Bergen, S. E., Ruderfer, D. M., Handsaker, R. E., McCarroll, S. A., O’Donovan, M. C., Owen, M. J., et al. (2012) Discovery and statistical genotyping of copy-number variation from whole-exome sequencing depth. Am. J. Hum. Genet., 91, 597-607

72. Coin, L. J., Cao, D., Ren, J., Zuo, X., Sun, L., Yang, S., Zhang, X., Cui, Y., Li, Y., Jin, X., et al. (2012) An exome sequencing pipeline for identifying and genotyping common CNVs associated with disease with application to psoriasis. Bioinformatics, 28, i370-i374

73. Li, A., Liu, Z., Lezon-Geyda, K., Sarkar, S., Lannin, D., Schulz, V., Krop, I., Winer, E., Harris, L. and Tuck, D. (2011) GPHMM: an integrated hidden Markov model for identification of copy number alteration and loss of heterozygosity in complex tumor samples using whole genome SNP arrays. Nucleic Acids Res., 39, 4928-4941

74. Yu, Z., Liu, Y., Shen, Y., Wang, M. and Li, A. (2014) CLImAT: accurate detection of copy number alteration and loss of heterozygosity in impure and aneuploid tumor samples using whole-genome sequencing data. Bioinformatics, 30, 2576-2583

75. Iqbal, Z., Caccamo, M., Turner, I., Flicek, P. and McVean, G. (2012) De novo assembly and genotyping of variants using colored de Bruijn graphs. Nat. Genet., 44, 226-232

76. Nijkamp, J. F., van den Broek, M. A., Geertman, J. M., Reinders, M. J., Daran, J. M. and de Ridder, D. (2012) De novo detection of copy number variation by co-assembly. Bioinformatics, 28, 3195-3202

77. Beroukhim, R., Getz, G., Nghiemphu, L., Barretina, J., Hsueh, T., Linhart, D., Vivanco, I., Lee, J. C., Huang, J. H., Alexander, S., et al. (2007) Assessing the significance of chromosomal aberrations in cancer: methodology and application to glioma. Proc. Natl. Acad. Sci. USA, 104, 20007-20012

78. Mermel, C. H., Schumacher, S. E., Hill, B., Meyerson, M. L., Beroukhim, R. and Getz, G. (2011) GISTIC2.0 facilitates sensitive and confident localization of the targets of focal somatic copy-number alteration in human cancers. Genome Biol., 12, R41

79. Sanchez-Garcia, F., Akavia, U. D., Mozes, E. and Pe'er, D (2010) JISTIC: identification of significant targets in cancer BMC Bioinformatics, 11, 189

80. Walter, V., Nobel, A.B., and Wright, F.A. (2011) DiNAMIC: A method to identify recurrent DNA copy number aberrations in tumors. Bioinformatics, 27, 678-685

81. Zhou, X., Liu, J., Wan, X. and Yu, W. (2014) Piecewise-constant and low-rank approximation for identification of recurrent copy number variations. Bioinformatics, 30, 1943-1949 
82. Xi, J. and Li, A. (2016) Discovering recurrent copy number aberrations in complex patterns via non-negative sparse singular value decomposition. IEEE/ACM Trans. Comp. Biol. Bioinfo., (TCBB)., 13, 656-668

83. Fanciulli, M., Petretto, E. and Aitman, T. J. (2010) Gene copy number variation and common human disease. Clin. Genet., 77, 201-213

84. Aldred, P. M., Hollox, E. J. and Armour, J. A. (2005) Copy number polymorphism and expression level variation of the human alpha-defensin genes DEFA1 and DEFA3. Hum. Mol. Genet., 14, 2045-2052

85. Breunis, W. B., van Mirre, E., Bruin, M., Geissler, J., de Boer, M., Peters, M., Roos, D., de Haas, M., Koene, H. R. and Kuijpers, T. W. (2008) Copy number variation of the activating FCGR2C gene predisposes to idiopathic thrombocytopenic purpura. Blood, 111, 1029-1038

86. Bayés, M., Magano, L. F., Rivera, N., Flores, R. and Pérez Jurado, L. A. (2003) Mutational mechanisms of Williams-Beuren syndrome deletions. Am. J. Hum. Genet., 73, 131-151

87. Marshall, C. R., Young, E. J., Pani, A. M., Freckmann, M. L., Lacassie, Y., Howald, C., Fitzgerald, K. K., Peippo, M., Morris, C. A., Shane, K., et al. (2008) Infantile spasms is associated with deletion of the MAGI2 gene on chromosome 7q11.23-q21.11. Am. J. Hum. Genet., 83, 106-111

88. Baldini, A. (2004) DiGeorge syndrome: an update. Curr. Opin. Cardiol., 19, 201-204

89. Bi, W., Yan, J., Stankiewicz, P., Park, S. S., Walz, K., Boerkoel, C. F., Potocki, L., Shaffer, L. G., Devriendt, K., Nowaczyk, M. J., et al. (2002) Genes in a refined Smith-Magenis syndrome critical deletion interval on chromosome $17 \mathrm{p} 11.2$ and the syntenic region of the mouse. Genome Res., 12, 713-728

90. Potocki, L., Chen, K. S., Park, S. S., Osterholm, D. E., Withers, M. A., Kimonis, V., Summers, A. M., Meschino, W. S., AnyaneYeboa, K., Kashork, C. D., et al. (2000) Molecular mechanism for duplication $17 \mathrm{p} 11.2$ - the homologous recombination reciprocal of the Smith-Magenis microdeletion. Nat. Genet., 24, 84-87

91. Stone, J. L., O’Donovan, M. C., Gurling, H., Kirov, G. K., Blackwood, D. H. R., Corvin, A., Craddock, N. J., Gill, M., Hultman, C. M., Lichtenstein, P., et al. (2008) Rare chromosomal deletions and duplications increase risk of schizophrenia. Nature, $455,237-241$

92. Stefansson, H., Rujescu, D., Cichon, S., Pietiläinen, O. P., Ingason, A., Steinberg, S., Fossdal, R., Sigurdsson, E., Sigmundsson, T., Buizer-Voskamp, J. E., et al. (2008) Large recurrent microdeletions associated with schizophrenia. Nature, 455, 232-236

93. de Vries, B. B., Pfundt, R., Leisink, M., Koolen, D. A., Vissers, L. E., Janssen, I. M., Reijmersdal, S., Nillesen, W. M., Huys, E. H., Leeuw, N., et al. (2005) Diagnostic genome profiling in mental retardation. Am. J. Hum. Genet., 77, 606-616

94. Friedman, J. M., Baross, Á., Delaney, A. D., Ally, A., Arbour, L., Asano, J., Bailey, D. K., Barber, S., Birch, P., Brown-John, M., et al. (2006) Oligonucleotide microarray analysis of genomic imbalance in children with mental retardation. Am. J. Hum.
Genet., 79, 500-513

95. Marshall, C. R., Noor, A., Vincent, J. B., Lionel, A. C., Feuk, L., Skaug, J., Shago, M., Moessner, R., Pinto, D., Ren, Y., et al. (2008) Structural variation of chromosomes in autism spectrum disorder. Am. J. Hum. Genet., 82, 477-488

96. Koolen, D. A., Sharp, A. J., Hurst, J. A., Firth, H. V., Knight, S. J., Goldenberg, A., Saugier-Veber, P., Pfundt, R., Vissers, L. E., Destrée, A., et al. (2008) Clinical and molecular delineation of the 17q21.31 microdeletion syndrome. J. Med. Genet., 45, 710720

97. Sharp, A. J., Mefford, H. C., Li, K., Baker, C., Skinner, C., Stevenson, R. E., Schroer, R. J., Novara, F., De Gregori, M., Ciccone, R., et al. (2008) A recurrent 15q13.3 microdeletion syndrome associated with mental retardation and seizures. Nat. Genet., 40, 322-328

98. Mefford, H. C., Sharp, A. J., Baker, C., Itsara, A., Jiang, Z., Buysse, K., Huang, S., Maloney, V. K., Crolla, J. A., Baralle, D., et al. (2008) Recurrent rearrangements of chromosome 1q21.1 and variable pediatric phenotypes. N. Engl. J. Med., 359, 16851699

99. Shaffer, L. G., Theisen, A., Bejjani, B. A., Ballif, B. C., Aylsworth, A. S., Lim, C., McDonald, M., Ellison, J. W., Kostiner, D., Saitta, S., et al. (2007) The discovery of microdeletion syndromes in the post-genomic era: review of the methodology and characterization of a new 1q41q42 microdeletion syndrome. Genet. Med., 9, 607-616

100. Butler, M. G., Meaney, F. J., Palmer, C. G., Opitz, J. M. and Reynolds, J. F. (1986) Clinical and cytogenetic survey of 39 individuals with Prader-Labhart-Willi syndrome. Am. J. Med. Genet., 23, 793-809

101. Chen, K. S., Manian, P., Koeuth, T., Potocki, L., Zhao, Q., Chinault, A. C., Lee, C. C. and Lupski, J. R. (1997) Homologous recombination of a flanking repeat gene cluster is a mechanism for a common contiguous gene deletion syndrome. Nat. Genet., 17, 154-163

102. Pérez Jurado, L. A., Peoples, R., Kaplan, P., Hamel, B. C. and Francke, U. (1996) Molecular definition of the chromosome 7 deletion in Williams syndrome and parent-of-origin effects on growth. Am. J. Hum. Genet., 59, 781-792

103. Edelmann, L., Pandita, R. K., Spiteri, E., Funke, B., Goldberg, R., Palanisamy, N., Chaganti, R. S., Magenis, E., Shprintzen, R. J. and Morrow, B. E. (1999) A common molecular basis for rearrangement disorders on chromosome 22q11. Hum. Mol. Genet., 8, 1157-1167

104. Bassett, A. S. and Chow, E. W. C. (2008) Schizophrenia and 22q11.2 deletion syndrome. Curr. Psychiatry Rep., 10, 148-157

105. Walters, R., Jacquemont, S., Valsesia, A., de Smith, A.J., Martinet, D., Andersson, J., Falchi, M., Chen, F., Andrieux, J., Lobbens, S., et al. (2010) A new highly penetrant form of obesity due to deletions on chromosome 16p11. 363 Nature. 463, 671675

106. Barbieri, C. E., Baca, S. C., Lawrence, M. S., Demichelis, F., Blattner, M., Theurillat, J. P., White, T. A., Stojanov, P., Van Allen, E., Stransky, N., et al. (2012) Exome sequencing identifies 
recurrent $S P O P, F O X A 1$ and MED12 mutations in prostate cancer. Nat. Genet., 44, 685-689

107. Kerdpon, D., Sriplung, H. and Kietthubthew, S. (2001) Expression of p53 in oral squamous cell carcinoma and its association with risk habits in southern Thailand. Oral Oncol., 37, 553557

108. Topcu, Z., Chiba, I., Fujieda, M., Shibata, T., Ariyoshi, N., Yamazaki, H., Sevgican, F., Muthumala, M., Kobayashi, H. and Kamataki, T. (2002) CYP2A6 gene deletion reduces oral cancer risk in betel quid chewers in Sri Lanka. Carcinogenesis, 23, 595598

109. India Project Team of the International Cancer Genome Consortium. (2013) Mutational landscape of gingivo-buccal oral squamous cell carcinoma reveals new recurrently-mutated genes and molecular subgroups. Nat Commun, 4, 2873

110. Pickering, C. R., Zhang, J., Yoo, S. Y., Bengtsson, L., Moorthy, S., Neskey, D. M., Zhao, M., Ortega Alves, M. V., Chang, K., Drummond, J., et al. (2013) Integrative genomic characterization of oral squamous cell carcinoma identifies frequent somatic drivers. Cancer Discov., 3, 770-781

111. Stransky, N., Egloff, A. M., Tward, A. D., Kostic, A. D., Cibulskis, K., Sivachenko, A., Kryukov, G. V., Lawrence, M. S., Sougnez, C., McKenna, A., et al. (2011) The mutational landscape of head and neck squamous cell carcinoma. Science, $333,1157-1160$

112. Salahshourifar, I., Vincent-Chong, V. K., Kallarakkal, T. G. and Zain, R. B. (2014) Genomic DNA copy number alterations from precursor oral lesions to oral squamous cell carcinoma. Oral Oncol., 50, 404-412

113. Murugan, A. K., Munirajan, A. K. and Tsuchida, N. (2013) Genetic deregulation of the PIK3CA oncogene in oral cancer. Cancer Lett., 338, 193-203

114. Freier, K., Schwaenen, C., Sticht, C., Flechtenmacher, C., Mühling, J., Hofele, C., Radlwimmer, B., Lichter, P. and Joos, S. (2007) Recurrent FGFR1 amplification and high FGFR1 protein expression in oral squamous cell carcinoma (OSCC). Oral Oncol., 43, 60-66

115. Martín-Ezquerra, G., Salgado, R., Toll, A., Gilaberte, M., Baró, T., Alameda Quitllet, F., Yébenes, M., Solé, F., Garcia-Muret, M., Espinet, B., et al. (2010) Multiple genetic copy number alterations in oral squamous cell carcinoma: study of $M Y C, T P 53, C C D N 1$, $E G F R$ and $E R B B 2$ status in primary and metastatic tumours. Br. J. Dermatol., 163, 1028-1035

116. Mendes, R. A. (2012) Oncogenic pathways in the development of oral cancer. J. Carcinog. Mutagen., 3, 2

117. Lee, J. A. and Lupski, J. R. (2006) Genomic rearrangements and gene copy-number alterations as a cause of nervous system disorders. Neuron, 52, 103-121

118. Cook, E. H. Jr and Scherer, S. W. (2008) Copy-number variations associated with neuropsychiatric conditions. Nature, 455, 919923

119. Kalatzis, V. and Antignac, C. (2002) Cystinosis: from gene to disease. Nephrol. Dial. Transplant., 17, 1883-1886

120. Stahl, E. A., Raychaudhuri, S., Remmers, E. F., Xie, G., Eyre, S., Thomson, B. P., Li, Y., Kurreeman, F. A., Zhernakova, A., Hinks, A., et al. (2010) Genome-wide association study meta-analysis identifies seven new rheumatoid arthritis risk loci. Nat. Genet., $42,508-514$

121. Jung, S. H., Yim, S. H., Hu, H. J., Lee, K. H., Lee, J. H., Sheen, D. H., Lim, M. K., Kim, S. Y., Park, S. W., Kim, S. H., et al. (2014) Genome-wide copy number variation analysis identifies deletion variants associated with ankylosing spondylitis. Arthritis Rheumatol., 66, 2103-2112

122. Kim, J. H., Jung, S. H., Bae, J. S., Lee, H. S., Yim, S. H., Park, S. Y., Bang, S. Y., Hu, H. J., Shin, H. D., Bae, S. C., et al. (2013) Deletion variants of $R A B G A P 1 L, 10 \mathrm{q} 21.3$, and $\mathrm{C} 4$ are associated with the risk of systemic lupus erythematosus in Korean women. Arthritis Rheum., 65, 1055-1063

123. Okada, Y., Wu, D., Trynka, G., Raj, T., Terao, C., Ikari, K., Kochi, Y., Ohmura, K., Suzuki, A., Yoshida, S., et al. (2014) Genetics of rheumatoid arthritis contributes to biology and drug discovery. Nature, 506, 376-381

124. de Cid, R., Riveira-Munoz, E., Zeeuwen, P. L., Robarge, J., Liao, W., Dannhauser, E. N., Giardina, E., Stuart, P. E., Nair, R., Helms, C., et al. (2009) Deletion of the late cornified envelope $L C E 3 B$ and $L C E 3 C$ genes as a susceptibility factor for psoriasis. Nat. Genet., 41, 211-215

125. Hüffmeier, U., Bergboer, J. G., Becker, T., Armour, J. A., Traupe, H., Estivill, X., Riveira-Munoz, E., Mössner, R., Reich, K., Kurrat, W., et al. (2010) Replication of $L C E 3 C-L C E 3 B C N V$ as a risk factor for psoriasis and analysis of interaction with other genetic risk factors. J. Invest. Dermatol., 130, 979-984

126. Xu, L., Li, Y., Zhang, X., Sun, H., Sun, D., Jia, X., Shen, C., Zhou, J., Ji, G., Liu, P., et al. (2011) Deletion of LCE3C and $L C E 3 B$ genes is associated with psoriasis in a northern Chinese population. Br. J. Dermatol., 165, 882-887

127. Veal, C. D., Reekie, K. E., Lorentzen, J. C., Gregersen, P. K., Padyukov, L. and Brookes, A. J. (2014) A 129-kb deletion on chromosome 12 confers substantial protection against rheumatoid arthritis, implicating the gene SLC2A3. Hum. Mutat., 35, 248256

128. Singleton, A. B., Farrer, M., Johnson, J., Singleton, A., Hague, S., Kachergus, J., Hulihan, M., Peuralinna, T., Dutra, A., Nussbaum, R., et al. (2003) $\alpha$-synuclein locus triplication causes Parkinson's disease. Science, 302, 841-841

129. Nagao, Y. (2015) Copy number variations play important roles in heredity of common diseases: a novel method to calculate heritability of a polymorphism. Sci. Rep., 5, 17156 